\title{
Evidence of Yersinia pestis DNA in rodents in plague outbreak foci in Mbulu and Karatu Districts, northern Tanzania
}

\author{
MICHAEL H. ZIWA ${ }^{1 *}$, MECKY I. MATEE ${ }^{1}$, BUKHETI S. KILONZO², BERNARD M. HANG'OMBE ${ }^{3}$ \\ ${ }^{1}$ Muhimbili University of Health and Allied Sciences, P.O. Box 65001 Dar es Salaam, Tanzania \\ ${ }^{2}$ Pest Management Centre, Sokoine University of Agriculture, P.O. Box 3110, Morogoro, Tanzania \\ ${ }^{3}$ University of Zambia, P.O. Box 32379, Lusaka, Zambia
}

\begin{abstract}
Human plague remains a public health concern in Tanzania despite its quiescence in most foci for years, considering the recurrence nature of the disease. Appreciable researches have involved serological screening of rodents, fleas and humans but none has involved molecular detection and hence proving the presence of Yersinia pestis in rodents in the most recent affected foci, Mbulu and Karatu districts in northern Tanzania. The objective of the current study was to employ a simple PCR to detect Yersinia pestis plasminogen activator (pla) gene in various potential mammalian hosts/reservoirs. The study was conducted in five villages in Mbulu and one in Karatu districts during the period of no disease outbreak. Rodents and small wild carnivores were captured, anaesthetized, identified, sexed and autopsied. Liver, spleen, heart and lung specimens were collected and DNA extracted after which PCR was used to detect the Y. pestis pla gene. A total of 517 small mammals were captured; of which, 493 (95.4\%) were from Mbulu and 24 (4.6\%) from Karatu. Two Mastomys natalensis (one from each district) and one Gerbilliscus sp. in Mbulu district were positive for $Y$. pestis pla gene. In conclusion, our results have provided a proof on the presence of $Y$. pestis in the two rodent species (Mastomys natalensis and Gerbilliscus sp.) and thus providing indicative evidence that the two are potential reservoirs of the pathogen and hence may be responsible for maintaining the same during periods of no disease outbreaks.
\end{abstract}

Key words: Human plague, Yersinia pestis, PCR, mammalian reservoirs, Tanzania

\section{Introduction}

Plague is an acute zoonotic bacterial disease caused by infection with Yersinia pestis. The bacterium is usually transmitted from one host to another through bites of infective fleas. Human infection usually occurs when these fleas escape from plague infected carcasses of domestic or wild animals especially rodents and bite humans (WHO, 2000; Neal, 2004). Humans can also contract the disease by droplet infection or direct contact with infected materials. In Africa, countries most affected include Madagascar, Democratic Republic of Congo, Mozambique, Uganda and Tanzania (Makundi et al., 2008). In Tanzania, the disease is believed to have been introduced in 1886 (Msangi, 1968 cited in Kilonzo et al., 2005). Since then outbreaks of the disease have occurred in various areas including Iringa, Bukoba, Musoma, Singida, Kondoa, Rombo, Hai, Arumeru, Mbulu, Same and Lushoto districts (Kilonzo et al., 2006). All these foci have experienced several outbreaks of the disease involving varying numbers of human cases and high case-fatality rates (Kilonzo, 1992). During the period 1953 to 2003 , a total of 8,956 plague cases with 731 (8.2\%) deaths, were reported from ten districts in the country (Kilonzo et al., 2005). Since 1980, however, only four districts (Lushoto, Singida, Karatu and Mbulu) have experienced outbreaks of the disease, involving 8,490 and 675 (8.0\%) cases and deaths, respectively (Kilonzo et al., 1997; 2006; Makundi et al., 2008).

The latest outbreaks of plague in Tanzania were reported in Mbulu District in the northern part of the country. The outbreak first occurred between February and March 2007, involving 35

\footnotetext{
${ }^{*}$ Correspondence: Michael H. Ziwa; Email: michael.ziwa@sacids.org
} 
human cases with 6 (17.1\%) recorded deaths (Makundi et al., 2008), and with more recent outbreaks occurring in the same focus in 2010 (allAfrica.com, 2010). Repeated outbreaks of plague in Mbulu district strongly suggest that the focus is active and that wild animals especially rodents of the class Muridae (rats and mice), and some other types of small mammals are probably responsible for maintaining the bacterium between outbreaks. Indeed earlier studies in the district revealed that several species of these animals were seropositive for the disease (Kilonzo, 1992; Makundi et al., 2008; Kilonzo \& Mtoi, 1983). Elsewhere other types of small mammals including rabbits, marmots and chipmunks also maintain the plague organism in the wilderness (Gage \& Kosoy, 2005).

In Mbulu and Karatu districts of Tanzania, available data on potential mammalian reservoirs of plague is based on serological studies using Enzyme Linked Immunosorbent Assay (ELISA), Passive Haemaglutination tests and Rapid Dipstick for detection of specific antibodies to Y. pestis Fraction I antigen (Kilonzo et al., 2005; 2006; Makundi et al., 2008). However, positive serological information suggests either current or previous infection of the animals with $Y$. pestis. The need to confirm the presence of the organisms in these potential reservoirs during non-epidemic periods is therefore desirable since such information is important in the control of plague. In this study Polymerase Chain Reaction (PCR) was used to detect $Y$. pestis DNA in potential mammalian hosts/reservoirs in two plague districts by amplifying the plasminogen activator/coagulase (pla) gene. This gene which is located on plasmid PPCP1, is incorporated into most $Y$. pestis PCR assays, and in several studies it has been used as the prime or sole marker (Riehmet al., 2011; Adjemian et al., 2008). Our reasons for including pla in our assay are its occurrence in multiple copies, its absence from closely related Yersinia species, and its role in Y. pestis virulence (Loïez et al., 2003; Tomaso et al., 2003).

\section{Materials and Methods}

\section{Study area}

The study was carried out in Mbulu and Karatu districts in northern Tanzania. Mbulu is located between latitudes $3.8^{\circ}$ and $4.5^{\circ} \mathrm{S}$, and between longitudes $35^{\circ}$ and $36^{\circ} \mathrm{E}$. The altitude ranges from 1000-2400m above sea level. The district contains areas having semi-arid and sub-humid climate that receive annual rainfall of greater than $400 \mathrm{~mm}$ and less than $1200 \mathrm{~mm}$, respectively. The 2012 National Census showed a population of 320,279 people comprised of 161,548 men and 158,731 women with an average of 6 people per household. Crop and livestock production are the most important economic activities, employing more than $90 \%$ of the total labour force (Ngowi et al., 2010).

Karatu is located between latitudes $3^{\circ} 10^{\prime}$ and $4^{\circ} 00^{\prime} \mathrm{S}$ and at longitude $34^{\circ} 47^{\prime} \mathrm{E}$. According to the 2012 National Census the district had a population of 230,166 people comprised of 117,769 men and 112,397 women with an average of 5 people per household. The district has three physicalgeographic zones namely upland, midland and lowland, with altitude ranging from 1000 to 1900m above sea level. Rainfall in the district is bimodal whereby short rains fall between October and December and long rains between March and June. Rainfall ranges from less than $400 \mathrm{~mm}$ in the Eyasi basin to over $1000 \mathrm{~mm}$ in the highlands with rainfall zones classified as semi-arid (300$700 \mathrm{~mm} /$ year) and sub-humid (700-1200mm), (Karatu District Council, unpubl).

In Mbulu district, five villages, namely, Arri, Mongahay, Hayeseng, Boboa and Mangisa were involved, while in Karatu, the study was carried out in Slahhamo village. Selection of the villages for the study was based on recent reports of plague outbreaks and informed consent of villagers. The selection was also based on lists of households provided by village leaders and special consideration was given to households which had plague victims during the outbreaks. 


\section{Specimen collection}

Live trapping of wild, peridomestic and commensal rodents, as well as wild small carnivores was carried out from January to August 2012 in Mbulu and from late October to early November 2012 in Karatu. Ten randomly selected households in each village were involved. Sherman and locally made box traps baited with peanut butter were used for catching wild, peridomestic and domestic rodents. On the other hand, locally made wire cage traps baited with pieces of meat, ripe bananas and tomatoes were used for catching giant rodents and wild small carnivores. Trapping was simultaneously carried out in two villages for three nights consecutively, using 100 Sherman and 8 wire cage traps in the forest and peridomestic areas as well as 25 box traps in the selected houses in each village. Security of traps and proven activities of such animals were considered.

Traps were usually set in the afternoon and inspected in the morning and those with captures were taken to a central processing location, where each animal was carefully transferred to a cloth bag and then to a screw-capped museum jar/bucket containing pieces of cotton wool soaked in anaesthetic ether in order to anaesthetize the animal and collect its ectoparasites. The animals were then identified, sexed and autopsied after removing their ectoparasites. Sections of liver, spleen, heart and lungs were collected and preserved in a screw-capped micro-tube containing absolute ethanol and appropriately labeled for laboratory analysis.

\section{Laboratory analysis}

Approximately 10mg of material was cut from each of the tissues stored in absolute ethanol and placed in a microcentrifuge tube, in which $95 \mu \mathrm{l}$ water, $95 \mu \mathrm{l} 2 \mathrm{X}$ digestion buffer and $10 \mu \mathrm{l}$ proteinase $\mathrm{K}$ were added. The contents were mixed and incubated at $55^{\circ} \mathrm{C}$ for 3 hours. A total of $700 \mu$ l of genomic lysis buffer was added and followed by vortexing and centrifugation at 10,000xg for one minute. The supernatant was transferred to a Zymo-Spin ${ }^{T M}$ IIC column in a collection tube and similarly centrifuged. Thereafter $200 \mu$ l of DNA pre-wash buffer was added to the spin column in a new collection tube and similarly centrifuged. Then $400 \mu \mathrm{l}$ of g-DNA wash buffer was added to a spin column and similarly centrifuged. Finally, the spin column was transferred to a clean microcentrifuge tube and $100 \mu \mathrm{l}$ of DNA elution buffer was added and incubated at room temperature for five minutes and then centrifuged at $17,000 x g$ for 30 seconds. The eluted DNA was finally stored at $-20^{\circ} \mathrm{C}$ until the time for assay.

\section{DNA extraction and detection of $Y$. pestis}

DNA was extracted using the DNA extraction kit (ZR genomic DNA ${ }^{\mathrm{TM}}$-Tissue MiniPrep Catalog No. D3051) following the manufacturer's instructions (Zymo Research Irvine, CA, USA). Detection of $Y$. pestis was accomplished using the conventional $P C R$ technique. The $Y$. pestis specific primers (Hinnebusch \& Schwan, 1993) were used to target the plasminogen activator (pla) gene of Y. pestis virulence plasmid pCP1. Yp pla1: (5'- ATC TTACTT TCC GTG AGA AG -3') and Yp plaz: (5'- CTT GGA TGT TGA GCT TCC TA -3') corresponding to nucleotides 971 to 990 and 1431 to 1450 of the pla locus sequence, respectively. PCR was performed by using a PCR machine (GeneAmp PCR System 9700) in a total reaction volume of $25 \mu \mathrm{l}$ comprising of $0.125 \mu \mathrm{l}$ ExTaq, $2.5 \mu \mathrm{l} 10 X P C R$ buffer, $1.5 \mu \mathrm{l} \mathrm{MgCl} 2,2.0 \mu \mathrm{l}$ dNTP, $100 \mu \mathrm{M}$ of Forward and Reverse primers each, $14.875 \mu \mathrm{l} \mathrm{PCR}$ water and $2.0 \mu \mathrm{l}$ of the Template DNA. Briefly the PCR test was accomplished as follows; initial denaturation at $94^{\circ} \mathrm{C}$ for $1 \mathrm{~min}$, subsequently $35 \mathrm{cycles}$ of denaturation at $94^{\circ} \mathrm{C}$ for $20 \mathrm{~s}$, annealing at $55^{\circ} \mathrm{C}$ for $15 \mathrm{~s}$, elongation at $72^{\circ} \mathrm{C}$ for $30 \mathrm{~s}$ and final elongation at $72^{\circ} \mathrm{C}$ for $5 \mathrm{~min}$. The system was then allowed to cool and held at $4{ }^{\circ} \mathrm{C}$. The correct sizes of the PCR products/bands were then confirmed in agarose gel electrophoresis and the UV illuminator. 


\section{Ethical considerations}

Ethical clearance Ref. No. MU/PGS/SAEC/Vol. VI/195 was granted by the Institutional Review Board of the Muhimbili University of Health and Allied Sciences. Permission to conduct the study in Mbulu and Karatu districts was granted by the respective District Executive Directors.

\section{Results}

\section{Species and number of small mammals captured}

A total of 517 small mammals were captured; of which, 154 (29.8\%), 148 (28.6\%), 85 (16.4\%), 63 (12.2\%) and 43 (8.3\%) were from Mongahay, Arri, Boboa, Hayeseng and Mangisa villages, respectively, in Mbulu district, whereas 24 (4.6\%) were from Slahhamo village in Karatu district (Table 1). All the mammals (100\%) captured in Karatu were rodents while 476 (96.6\%), 8 (1.6\%) and 9 (1.8\%) captured from Mbulu were rodents, wild small carnivores and shrews, respectively. Of the 517 mammals caught, $52.4 \%$ were males and $47.6 \%$ were females, respectively.

Table 1: Species and number of small mammals captured in Mbulu and Karatu districts

\begin{tabular}{|c|c|c|c|c|c|c|c|c|}
\hline & & & Mbulu & & & Karatu & Total & $\%$ \\
\hline Species/Village & Mongahay & Arri & Hayeseng & Boboa & Mangisa & Slahhamo & & \\
\hline $\begin{array}{l}\text { Mastomys natalensis } \\
\text { Lophuromys }\end{array}$ & 56 & 41 & 17 & 15 & 17 & 6 & 152 & 29.4 \\
\hline flavopunctatus & 27 & 27 & 11 & 28 & 0 & 0 & 93 & 18.0 \\
\hline Rattus rattus & 22 & 34 & 15 & 13 & 0 & 9 & 93 & 18.0 \\
\hline Praomys delectorum & 30 & 21 & 12 & 17 & 0 & 0 & 80 & 15.5 \\
\hline Lemniscomys striatus & 5 & 7 & 4 & 3 & 0 & 6 & 25 & 4.8 \\
\hline Aethomys sp. & 0 & 0 & 0 & 3 & 15 & 0 & 18 & 3.5 \\
\hline Grammomys sp. & 1 & 6 & 2 & 1 & 6 & 3 & 19 & 3.7 \\
\hline Croccidura sp. & 4 & 3 & 0 & 2 & 0 & 0 & 9 & 1.7 \\
\hline Mus minutoides & 2 & 3 & 1 & 1 & 1 & 0 & 8 & 1.5 \\
\hline Graphiurus murinus & 6 & 1 & 0 & 0 & 0 & 0 & 7 & 1.4 \\
\hline Gerbilliscus sp. & 0 & 0 & 0 & 0 & 1 & 0 & 1 & 0.2 \\
\hline Arvicanthis niloticus & 0 & 0 & 0 & 0 & 1 & 0 & 1 & 0.2 \\
\hline Cricetomys gambianus & 0 & 3 & 0 & 0 & 0 & 0 & 3 & 0.6 \\
\hline Herpestes sanguinea & 0 & 2 & 1 & 1 & 0 & 0 & 4 & 0.8 \\
\hline Genetta genetta & 1 & 0 & 0 & 1 & 2 & 0 & 4 & 0.8 \\
\hline Total & 154 & 148 & 63 & 85 & 43 & 24 & 517 & 100.0 \\
\hline$\%$ & $29.8 \%$ & $28.6 \%$ & $12.2 \%$ & $16.4 \%$ & $8.3 \%$ & $4.6 \%$ & & 100.0 \\
\hline
\end{tabular}

\section{Laboratory observations from PCR tests}

Two rodents (one Mastomys natalensis and one Gerbilliscus sp.) captured in Mbulu district and one Mastomys natalensis captured from Karatu district were found to be positive for $Y$. pestis pla gene (Table 2) where the expected 478bp segment of the gene was successfully amplified (Figure 1). The Y. pestis positive rodents in Mbulu district were captured from Mangisa village. Two (66.7\%) of the three $Y$. pestis positive rodents were females with each one being captured from Mbulu and Karatu districts. 
Table 2: Species and number of small mammals tested for Y. pestis pla gene in Mbulu and Karatu districts

\begin{tabular}{lccc} 
Species & Number tested & Plague positive & Percentage \\
\hline Mastomys natalensis & 152 & 2 & 1.3 \\
Lophuromys flavopunctatus & 93 & 0 & 0 \\
Rattus rattus & 93 & 0 & 0 \\
Praomys delectorum & 80 & 0 & 0 \\
Lemniscomys striatus & 25 & 0 & 0 \\
Aethomys sp. & 18 & 0 & 0 \\
Grammomys sp. & 19 & 0 & 0 \\
Croccidura sp. & 9 & 0 & 0 \\
Mus minutoides & 8 & 0 & 0 \\
Graphiurus murinus & 7 & 0 & 0 \\
Gerbilliscus sp. & 1 & 1 & 100 \\
Arvicanthis niloticus & 1 & 0 & 0 \\
Cricetomys gambianus & 3 & 0 & 0 \\
Herpestes sanguinea & 4 & 0 & 0 \\
Genetta genetta & 4 & 0 & 0.6 \\
\hline Total & $\mathbf{5 1 7}$ & $\mathbf{0}$ \\
\hline
\end{tabular}

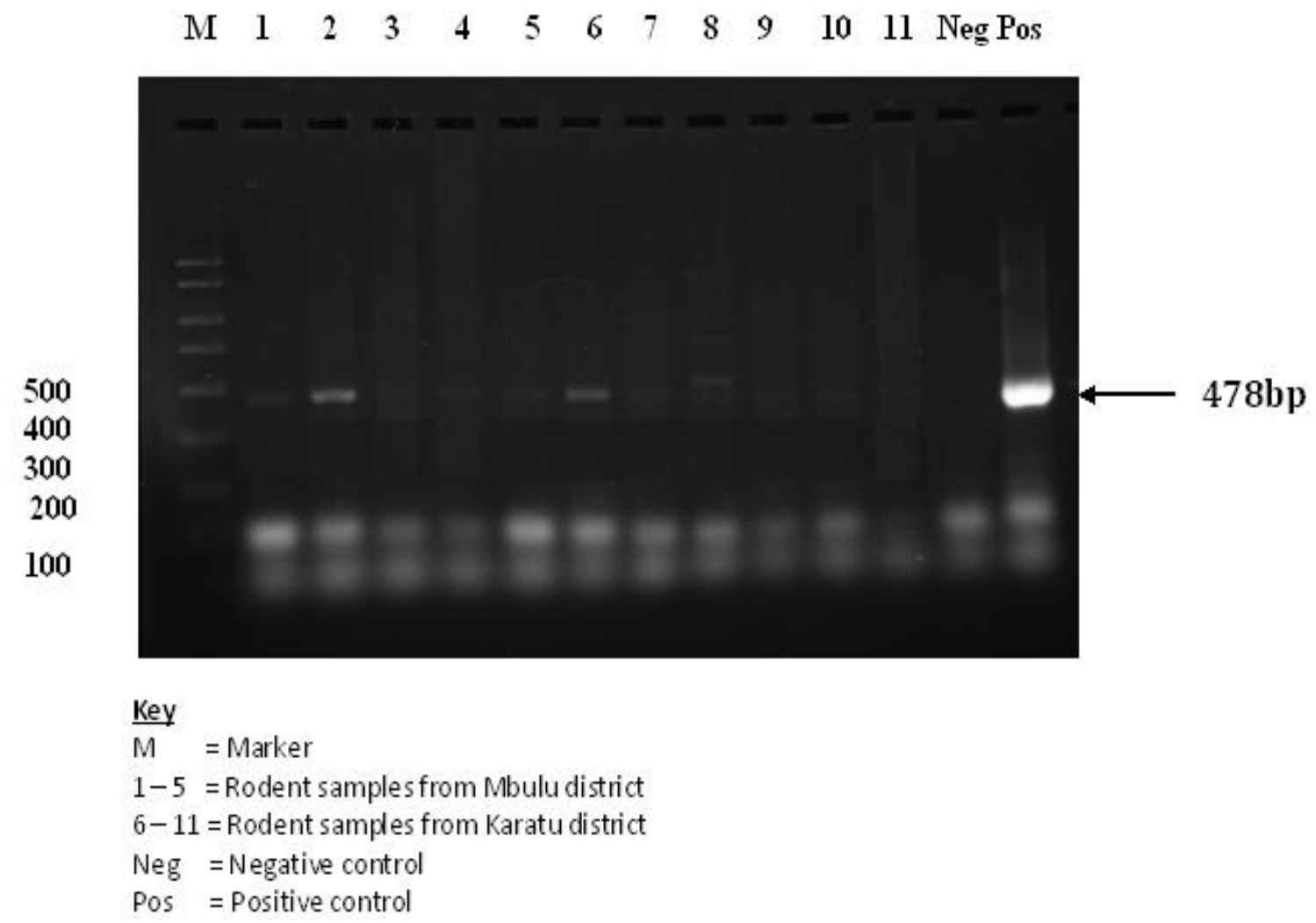

Figure 1: PCR detection of $Y$. pestis pla gene in rodents captured in Mbulu and Karatu districts 


\section{Discussion}

This study employed PCR to detect $Y$. pestis by targeting the plasmid encoded plasminogen activator (pla) gene, which is responsible for two activities of virulent $Y$. pestis. The virulence attributes of this gene include; plasminogen activation that result in lysis of fibrin clots, and weak coagulase activity. The gene is unique to and highly conserved in Y. pestis (Hinnebusch \& Schwan, 1993). The PCR assay targeting this gene has been used by various researchers in similar studies (Stevenson et al., 2003; Griffin et al., 2010; Hang'ombe et al., 2012). In this study Y. pestis was detected in three (0.6\%) rodents (two Mastomys natalensis and one Gerbilliscus sp.); of these two were females; thus providing a direct evidence on the presence of $Y$. pestis in potential host mammals. These results further provide indicative evidence on the involvement of these animal species as reservoirs of the bacterium in the two districts and possibly in other plague endemic foci in Tanzania as previously described (Kilonzo \& Mtoi, 1983; Kilonzo et al., 2005; Makundi et al., 2008). In a recent study by Haule et al. (2013) Mastomys natalensis was identified as one of the most abundant rodent species and that it was highly infested by fleas.

The fact that neither of the positive rodents was infested with fleas, that the positive animals had no clinical signs for plague and the disease was quiescent during the time of specimen collection suggest that the pathogen is circulating between various hosts in the areas and that these hosts are relatively resistant to the lethal effects of the pathogen and are presumably responsible for maintenance of the pathogen in the sylvatic cycle (Neal, 2004; Davis et al., 2006). Indeed plague outbreaks are seasonal and they most often occur when the necessary conditions prevail and are primarily effected via the bites of infective fleas (Eisen et al., 2007; Hang'ombe et al., 2012).

The overall infection rate (0.6\%) obtained in this study was relatively low when compared with results from similar studies from other areas (Riehm et al., 2011; Hang'ombe et al., 2012). In their studies, Riehm and Hang'ombe independently, got overall infection rates of $5.3 \%$ and $6.0 \%$, respectively. Such differences in infection rates between our and previous similar studies could be attributable, at partly, by the fact that we conducted our study during the period of disease quiescence and possibly also due to the geographical-related differences and seasonality. In fact plague transmission in Tanzania and elsewhere is usually seasonal and in some foci, outbreaks normally occur in November to March and peaks are observed between December and February with strong inter-annual variations (WHO, 2006; Hang'ombe et al., 2012). On the other hand, according to our findings the infection rate was relatively higher in female rodents (66.7\%) than in males. Such findings could have an implication on the disease dynamics due to the fact that, when a female rodent bears offspring she lives together with the later in the burrow/nest hence they could become infested with $Y$. pestis infected fleas. If that happens and when this new generation grows up and start their lives they become modes of plague pathogen reservoirs and can transfer infected fleas from one area to another.

On the basis of these results we conclude that $Y$. pestis is circulating among others in Mastomys natalensis and Gerbilliscus sp. in Mbulu and Karatu districts; that the two rodent species are likely to be responsible for maintaining the pathogen during periods of no disease outbreak. Presence of the pathogen during the period of disease quiescence implies that continuing outbreaks should be expected whenever conditions become favorable and hence necessary preventive measures and emergency preparedness plans should be put in place. We noted that female rodents have a higher infection rate, a fact that may be taken into consideration when prioritizing infection control measures. 


\section{Acknowledgements}

We wish to thank Mr. Ginethon Mhamphi and Mr. Halid Kibwana of the Sokoine University of Agriculture Pest Management Centre (SPMC) for their technical assistance during the field activities. Our exceptional thanks are due to Mr. Evans Mulenga and Mr. Ladslav Moonga of the Microbiology Laboratory, Department of Paraclinical Studies, School of Veterinary Medicine, University of Zambia, for their technical assistance in the laboratory procedures. Last but not least, we wish to express our unlimited appreciations to the Director (SPMC) for provision of field equipment, the Deans (FVMSUA and School of Veterinary Medicine University of Zambia) for authorizing the use of laboratory facilities. This study received financial assistance from the Wellcome Trust through the Southern African Centre for Infectious Disease Surveillance.

\section{References}

Adjemian, J.Z., Adjemian, M.K., Foley, P., Chomel, B.B., Kasten, R.W. \& Foley, J.E. (2008) Evidence of multiple zoonotic agents in a wild rodent community in the eastern Sierra Nevada. Journal of Wildlife Diseases 44, 737-742.

Davis, S., Makundi, R.H., Machang'u, R.S. \& Leirs, H. (2006) Demographic and spatiotemporal variation in human plague at a persistent focus in Tanzania. Acta Tropica 100, 133-141.

Eisen, R.J., Lowell, J.L., Montenieri, J.A., Bearden, S.W. \& Gage, K.L. (2007) Temporal dynamics of early-phase transmission of Yersinia pestisby unblocked fleas: secondary infectious feeds prolong efficient transmission by Oropsyllamontana (Siphonaptera: Ceratophyllidae). Journal of Medical Entomology 44, 672-677.

Gage, K.L., \& Kosoy, M.Y. (2005) Natural history of plague perspectives from more than a century of research. Annual Review of Entomology 50, 505-528.

Griffin, K.A., Martin, D.J., Rosen, L.E., Sirochman, M.A., Walsh, D.P., Wolfe, L.L. \& Miller, M.W. (2010) Detection of Yersinia pestis DNA in Prairies Dog - associated fleas by Polymerase Chain Reaction of Purified DNA. Journal of Wildlife Disease 46, 636-643.

Hang'ombe, B.M., Nakamura, I., Samui, K.L., Kaile, D., Mweene, A.S., Kilonzo, B.S., Sawa, H., Sugimoto, C. \& Wren, B.W. (2012). Evidence of Yersinia pestis DNA from fleas in an endemic plague area of Zambia: BMC Research Notes 5, 72.

Haule, M., Lyamuya, E.F., Matee, M.I., Kilonzo, B.S. \& Hang'ombe, B.N. (2013)Factors associated with flea infestation among the different rodent species in Mbulu and Karatu districts, northern Tanzania. Tanzania Journal of Health Research 15 (3).

Hinnebusch, J., \& Schwan, T.G. (1993) New Method for Plague Surveillance using Polymerase Chain Reaction to detect Yersinia pestisin fleas. Journal of Clinical Microbiology 31, 1511-1514.

Kilonzo, B.S., \& Mtoi, R.S. (1983) Entomological, bacteriological and serological observations after the 1977 plague outbreak in Mbulu District-Tanzania. East African Medical Journal 60, 91-97.

Kilonzo, B.S. (1992) Observation on the epidemiology of plague in Tanzania during the period 19741988. East African Medical Journal 69, 494-499.

Kilonzo, B.S., Mvena, Z.S.K., Machangu, R.S. \& Mbise, T.J. (1997) Preliminary observations on factors responsible for long persistence and continued outbreaks of plague in Lushoto district, Tanzania. ActaTropica 68, 215-227. 
Kilonzo, B.S., Mhina, J., Sabuni, C. \& Mgode, G. (2005) The role of rodents and small carnivores in plague endemicity in Tanzania. Belgium Journal of Zoology 135 (Suppl.), 119-125.

Kilonzo, B.S., Mbise, T.J., Mwalimu, D.C. \& Kindamba, L. (2006) Observations on the endemicity of plague in Karatu and Ngorongoro, northern Tanzania. Tanzania Health Research Bulletin 8, 1-6.

Loïez, C., Herwegh, S., Wallet, F., Armand, S., Guinet, F. \& Courcol, R.J. (2003) Detection of Yersinia pestis in sputum by real-time PCR. Journal of Clinical Microbiology 41, 4873-4875.

Makundi, R.H., Massawe, A.W., Mulungu, L.S., Katakweba, A., Mbise, T.J. \& Mgode, G. (2008) Potential mammalian reservoirs in a bubonic plague outbreak focus in Mbulu District, northern Tanzania. Mammalia 72, 253-257.

Neal, R.C. (2004) Transmission cycles of plague. ASM Microbe Library.

Ngowi, H.A., Kassuku, A.A., Carabin, H., Mlangwa, J.E.D. \& Mlozi, M.R.S. (2010) Spatial clustering of porcine cysticercosis in Mbulu District, northern Tanzania. PLoS Neglected Tropical Diseases 4(4), e652.

Riehm, J.M., Tserennorov, D., Kiefer, D., Stuermer, I.W., Tomaso, H. \& Zoller, L. (2011) Yersinia pestis in small rodents, Mongolia. Emerging Infectious Diseases 17, 1320-1322.

Stevenson, L.H., Bai, Y., Kosoy, M.Y., Montenieri, A.J., Lowell, J.L., Chu, C.M. \& Gage, L.K. (2003) Detection of novel Bartonella strains and Yersinia pestis in prairie dogs and their fleas (Siphonaptera: Ceratophyllidae and Pulicidae) using multiplex polymerase chain reaction. Journal of Medical Entomology 40, 329-337.

Tomaso, H., Reisinger, E.C.A., Dahouk, S., Frangoulidis, D., Rakin, A. \& Landt, O. (2003) Rapid detection of Yersinia pestis with multiplex real-time PCR assay using fluorescent hybridization probes. FEMS Immunol Med Microbiol 38, 117-126.

WHO (2000) Report on Global Surveillance of epidemic-prone Infectious Diseases-Plague. World Health Organization. WHO/CDS/CSR/ISR/2000.1

World Health Organization (2006) Inter-regional Meeting on Prevention and Control of Plague. Antananarivo, Madagascar, 7-14 April; Global Alert and Response. 